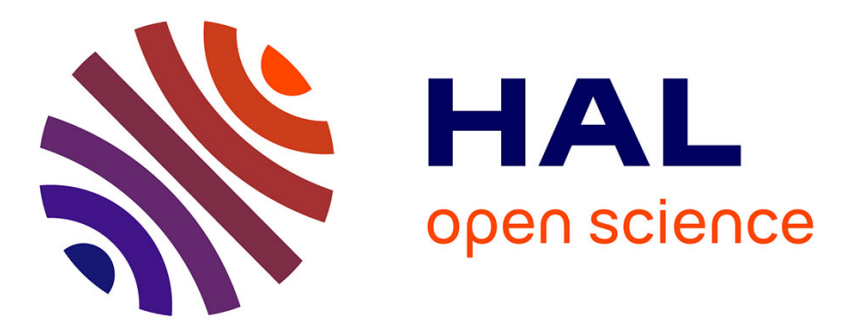

\title{
Les élections législatives de décembre 2016 en Côte d'Ivoire sous le signe de la démobilisation
}

Christian Bouquet

\section{To cite this version:}

Christian Bouquet. Les élections législatives de décembre 2016 en Côte d'Ivoire sous le signe de la démobilisation. Afrique Contemporaine, 2017, 263-264, pp.240-241. 10.3917/afco.263.0240 . halshs02285510

\section{HAL Id: halshs-02285510 \\ https://shs.hal.science/halshs-02285510}

Submitted on 12 Sep 2019

HAL is a multi-disciplinary open access archive for the deposit and dissemination of scientific research documents, whether they are published or not. The documents may come from teaching and research institutions in France or abroad, or from public or private research centers.
L'archive ouverte pluridisciplinaire HAL, est destinée au dépôt et à la diffusion de documents scientifiques de niveau recherche, publiés ou non, émanant des établissements d'enseignement et de recherche français ou étrangers, des laboratoires publics ou privés. 


\section{Les élections législatives de décembre 2016 en Côte d'Ivoire sous le signe de la démobilisation}

\section{Christian Bouquet}

Professeur émérite de géographie politique à l'université Bordeaux-Montaigne et chercheur au laboratoire LAM « Les Afriques dans le Monde » (Sciences Po Bordeaux).

Conformément au calendrier électoral réinitialisé en 2011, des élections législatives se sont tenues le 18 décembre 2016 pour renouveler les 255 sièges de députés pourvus lors des élections précédentes de novembre 2011.

Pour cette consultation, les autorités n’ont pratiquement rien changé aux mécanismes en place. La Commission électorale indépendante (CEI), chargée de l'organisation du scrutin, a peu bougé depuis 2010, le découpage des circonscriptions tel qu'il avait été redessiné en 2011 a été maintenu ${ }^{1}$, et le fichier électoral, déjà fort incomplet en 2015, a encore été réduit par rapport au nombre des inscrits pour le référendum d'octobre 2016, car on n'a actualisé que la liste des électeurs vivants...

En revanche, ces élections ont été inclusives car, pour la première fois depuis 2010, le Front populaire ivoirien (FPI) a renoncé au boycott systématique qu'il prônait « tant que Gbagbo ne serait pas libéré », selon les mots de Laurent Akoun, l'un des leaders du FPI « radical » (qui est d'ailleurs resté sur cette position). La participation du principal parti d'opposition a donc changé les données de l'équation, car les élections législatives en Côte d'Ivoire ne se jouent que sur un seul tour.

Les alliés du Rassemblement des houphouëtistes pour le développement et la paix (RHDP), qui avaient profité du boycott des gbagbistes en 2011 pour se présenter en ordre dispersé, ont ainsi dû réactiver le principe de l'investiture commune sur les 205 circonscriptions.

Cet exercice ne fut pas réalisé sans accrocs, et, sur 1391 candidats déclarés, 789 s’inscrivirent sous l'étiquette «Indépendants », parmi lesquels 192 étaient en réalité des dissidents du RDR

\footnotetext{
${ }^{1}$ Voir Christian Bouquet et Irène Kassi-Djodjo, « Les élections locales 2013 en Côte d'Ivoire : des malentendus subsistent sur l'exercice de la démocratie », EchoGéo, n² 27, 13 janvier 2014.
} 
qui n'avaient pas été investis par le parti, et 150 étaient dans la même situation par rapport au PDCI.

Les opérations électorales se sont déroulées sans incident majeur - et sans véritable ferveur - le 18 décembre 2016. Sur 6268113 électeurs inscrits, seulement 2137364 se rendirent aux urnes, soit une participation de 34,10\%, en baisse de deux points par rapport à 2011 .

Publiés dès le 21 décembre, les résultats affichèrent donc surtout une très forte abstention, notamment dans le district d'Abidjan, où la plupart des communes ne dépassèrent pas $20 \%$ de votants. Comme lors du référendum organisé six semaines plus tôt, c'est dans les régions nord que les électeurs se sont le plus mobilisés (voir carte 1). Comme souvent, l'électorat rural s'est exprimé plus massivement (90,51 \% à Kong) que l'électorat urbain (10,87 \% à Yopougon).

Sans surprise, le RHDP l'a emporté (167 sièges), mais la forte poussée des «Indépendants » (76 sièges) était moins attendue, de même que le très faible score du FPI ( 3 sièges, sur les 187 circonscriptions couvertes par ses candidats). La carte illustrant cette configuration donne donc une impression de raz-de-marée ${ }^{2}$, même si les députés relevant du RHDP étaient 235 lors de la précédente législature.

Mais, à l'ouverture de la première session parlementaire, les deux grands alliés du RHDP décidèrent de siéger sous leurs propres couleurs, et ce véritable coup de théâtre permit au paysage politique d'apparaître plus clairement (voir carte 2).

Grâce au ralliement de 29 «indépendants dissidents », le RDR compte désormais 129 députés, le PDCI en compte 89 (dont 23 « indépendants dissidents » ralliés) et les autres se répartissent entre quatre groupes parlementaires de 9 députés : UDPCI (Union pour la démocratie et le progrès en Côte d'Ivoire, ex-membre du RHDP), Nouvelle Vision, Vox Populi et Agir pour le peuple. Le FPI, pourtant très minoritaire (3 députés), a lui aussi éclaté entre deux des groupes parlementaires cités supra et un élu non inscrit.

Les principaux enseignements tirés de cette consultation concernent l'abstention, et notamment celle qui a touché les communes urbaines traditionnellement favorables au parti du président. Dans ces quartiers populaires, où le mécontentement peut rapidement devenir violent, le RDR semble avoir perdu la main. Globalement, il a d'ailleurs perdu des sièges par rapport à 2011 (129 contre 137) et ne dépasse la majorité absolue (128) que d'un siège. De son côté, le PDCI a gagné trois sièges ( 89 contre 86 ), mais il n'a pas perdu de vue que plusieurs investitures RHDP

\footnotetext{
${ }^{2}$ Voir les cartes de l'auteur sur le site : http://www.lam.sciencespobordeaux.fr/page/cote-divoire-legislatives
} 
ont été accordées indûment - selon eux - au RDR. Les autres groupes semblent fourbir leurs armes pour les prochaines échéances électorales. La mandature de la présente Assemblée nationale sera réduite à quatre ans pour correspondre à la prochaine élection présidentielle (2020).

Les élections intermédiaires (municipales et régionales) sont prévues pour 2018. Les élections sénatoriales ont eu lieu le 24 mars 2018.

\section{Élections législatives 2016 en Côte d'Ivoire}

Participation par département

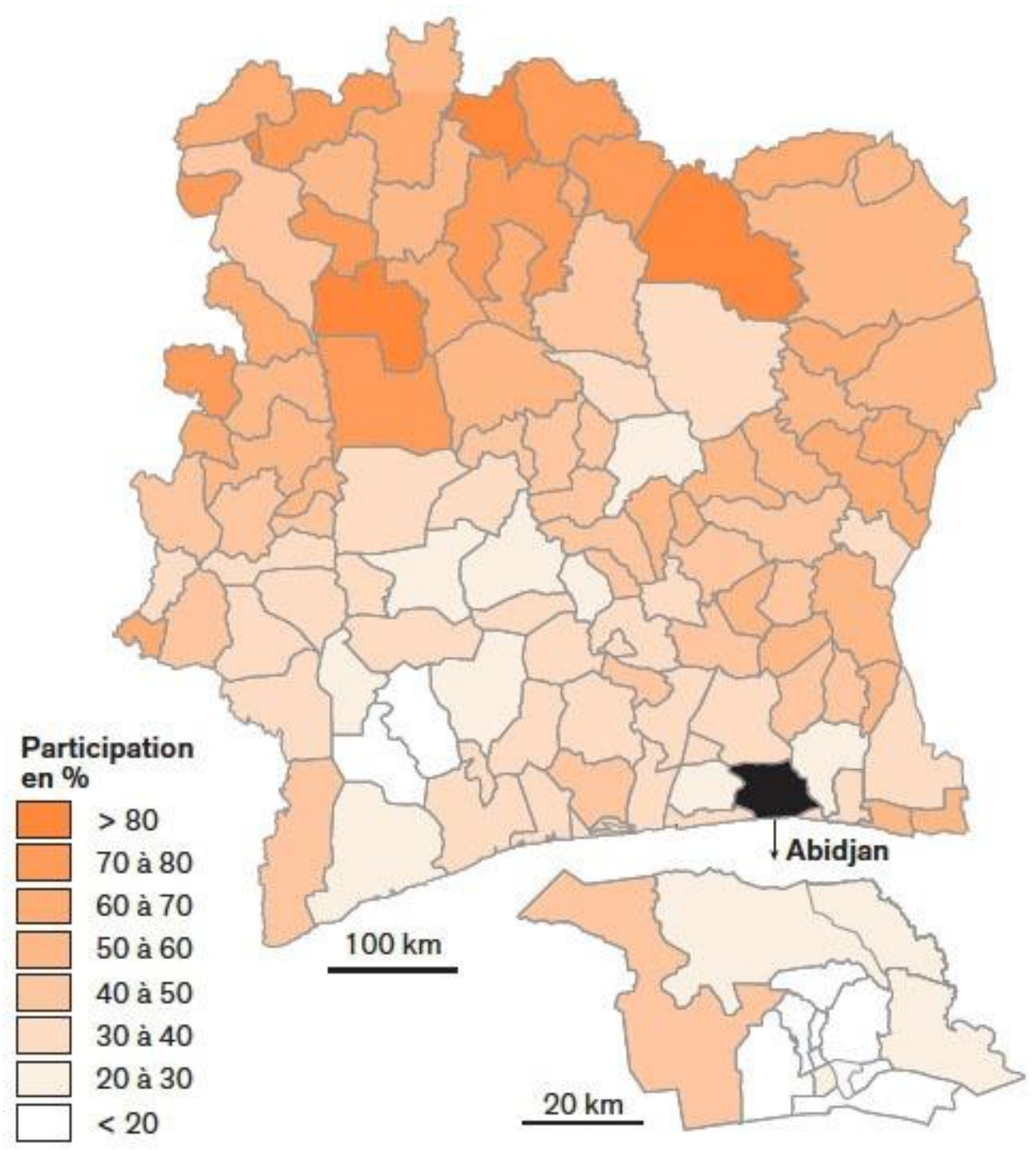


Résultats par département après la constitution des groupes parlementaires

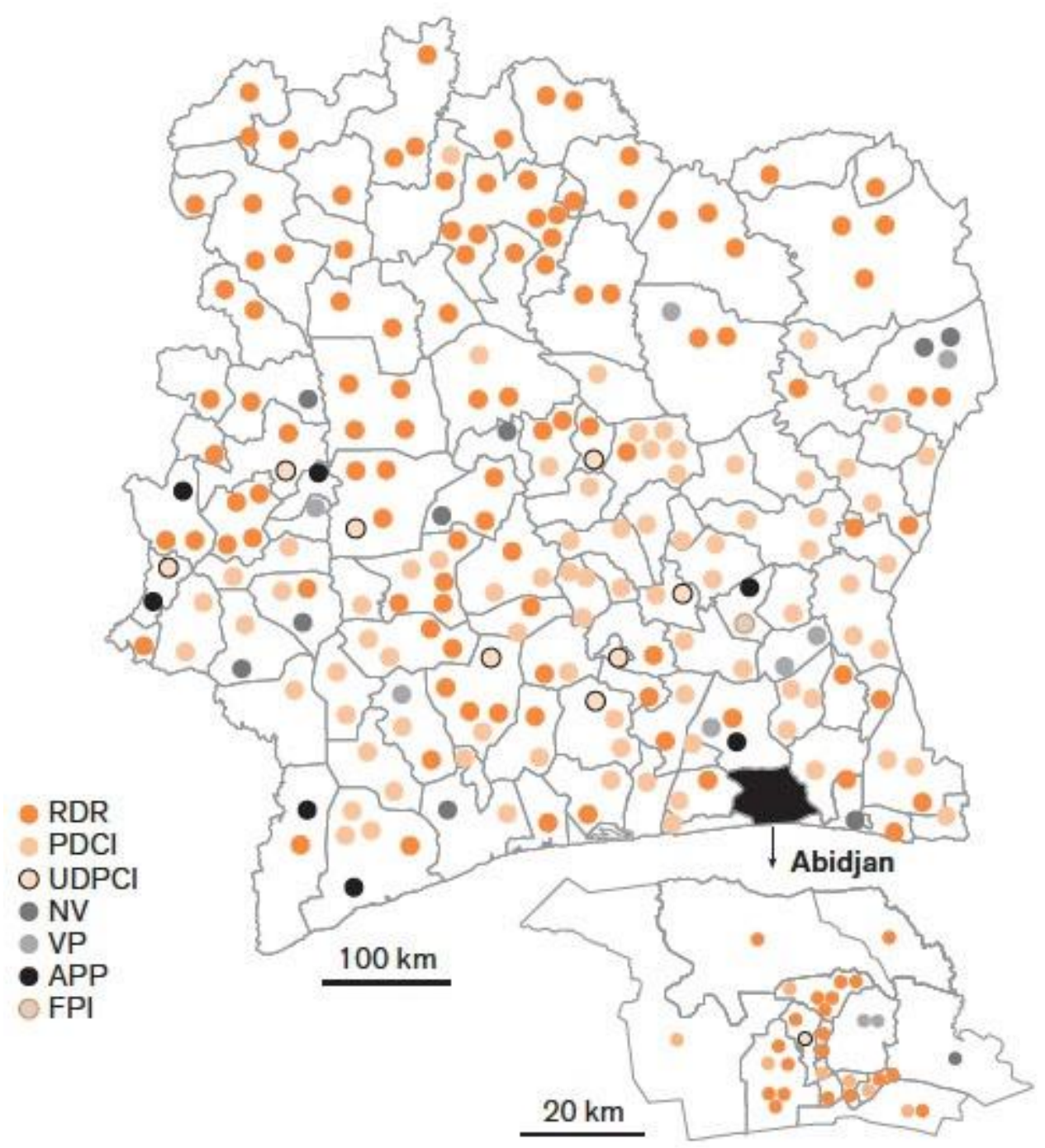

